\title{
THE APPLICATION OF ACOUSTIC ANISOTROPY TO EVALUATION OF MATERIAL PROPERTIES
}

\author{
Józef Krysztofik \\ Wojciech Manaj \\ Grzegorz Socha \\ Institute of Aviation, Al. Krakowska 110/114, 02-256 Warsaw, Poland \\ jozef.krysztofik@ilot.edu.pl, wojciech.manaj@ilot.edu.pl, grzegorz.socha@ilot.edu.pl
}

\begin{abstract}
Structural properties of materials change under stress, temperature and work environment. These changes are generally unfavorable. They cause a reduction in strength of materials. This has an impact on the safety and service life of machines and constructions.

In the chemical and petrochemical industry the destruction of a structure can be activated by chemical substances. In the energy industry, a key element in assisting the destruction is temperature. In aviation, the typical cause of damage is the process of fatigue. Regardless of the differences regarding/concerning the mechanisms of degradation, typical of the sectors of industry, the end result is the emergence of microvoids and microcracks in the material. In the final phase of the process, dominant cracks are formed.

The term of measure of material damage, introduced by Kachanov and Rabotnow, can be effectively used also when considering the impact of microdamages on measurable macroscopic acoustic quantities. A damage parameter proposed by Johnson allows to correlate changes in acoustic birefringence of the material with the parameter describing the degree of damage.

In this article the authors presented the nondestructive tests results concerning Inconel 718 alloy subjected to damage caused by plastic deformation. This paper focuses on the evaluation of acoustic properties in relation to the degradation of the materials tested.
\end{abstract}

Keywords: nondestructive testing, acoustic birefringence, damage parameter, Inconel 718.

\section{INTRODUCTION}

In aviation, depending on a material applied, the typical cause of component damage is fatigue processes associated with high temperatures, as in the case of engine elements. For this reason materials used are characterized by high mechanical strength and corrosion resistance, especially at elevated temperatures. One group of such materials is Inconel, a family of alloys with austenitic crystal structure based on nickel and chromium. Superalloys have a high heat resistance, strength and creep resistance at high temperatures, good surface stability and resistance to corrosion and oxidation. Therefore, Inconel alloys are particularly used in extreme conditions - in energy, aviation, and aerospace industries. Inconel, as any material during exploitation, is subjected to damage causing changes in properties such as fatigue resistance and dimensional stability. Due to their negative effect, these changes are known as degradation. Methods of material damage measurement are based on the assumption of the correlation between a degree of damage and measurable physical qualities of a material. To estimate this correlation a new type of specimens of variable cross-sectional area measuring part is used. This allows obtaining a continuous 
distribution of plastic strain in that part of the specimen. Deformation that varies along the axis of the sample enables analysis of damage induced by plastic deformation.

The study examined changes in acoustic birefringence of the material resulting from the given deformation. The correlation between the results of nondestructive testing and degree of material damage was obtained using the damage parameter proposed by Johnson. The presented testing method gives information on changes in the material structure caused by permanent deformation.

\section{THE ANISOTROPY OF THE ELASTIC PROPERTIES}

The anisotropy of the elastic properties is manifested by different velocities of propagation of ultrasonic waves in the material. These speeds are dependent on the direction of wave propagation in the material or their polarity. This type of anisotropy is known as acoustic birefringence. Acoustic anisotropy of the material may be characterized - (quantified) by the values of the algebraic combinations of velocities of different types of waves propagating in different directions and of different polarities.

For example, one parameter characterizing the anisotropy is the relative difference in transit time (velocity) of longitudinal waves propagating parallel and perpendicular to the direction of stress based on relations shown in Fig.1. [1], or a change in transit time (velocity) of transverse waves propagating in a direction perpendicular to the direction of stress of different polarities shown in Fig. 2 [1].

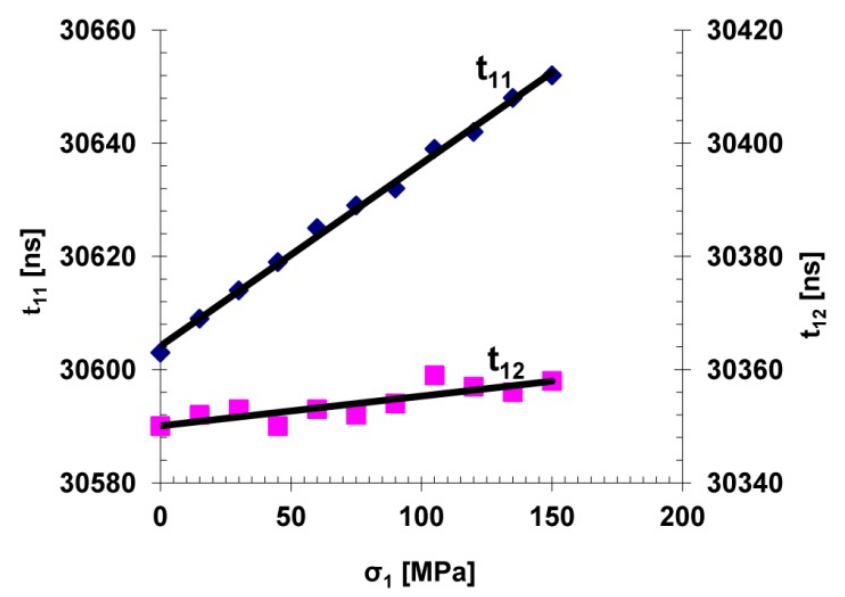

Figure 1. The relationship between stress and transit time of longitudinal wave $t_{11}$ and transverse wave $t_{12}$ propagating in the direction of stress $\sigma_{1}[1]$

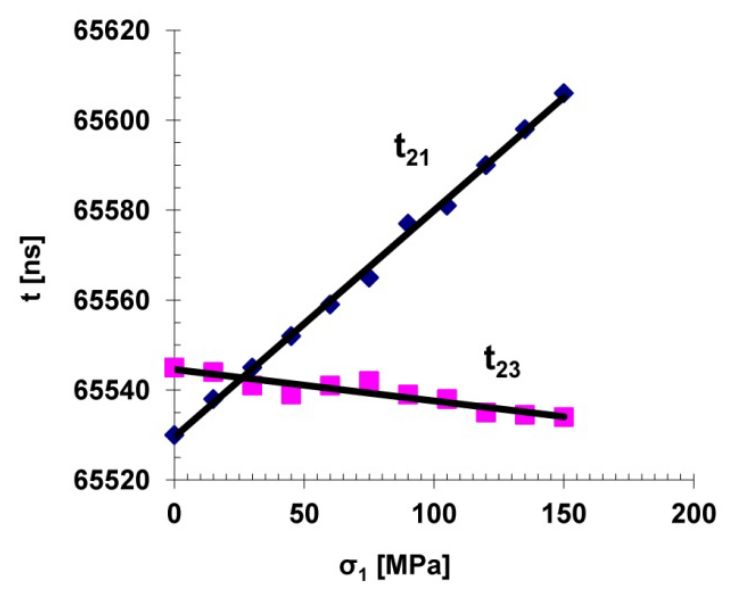

Figure 2. Changes in transit time of transverse waves propagating in a direction perpendicular to the direction of stress $\sigma_{1}$ and polarized in a direction of stress $t_{21}$ and perpendicular to the direction of stress $t_{23}$. [1] 
Changes of anisotropy of a material also occur during the development of the microstructure damage. These changes can be described by the acoustic birefringence parameter, which indicates the relative difference in speed between two transverse waves propagating in the same direction but having different, mutually orthogonal polarizations. Figure 3. shows the average values of acoustic birefringence obtained as a result of creep of the flat steel A336 specimen [6]. Measurements were carried out in the measuring part $\mathrm{B}$ and the gripping part $\mathrm{B}_{0}$ of the specimen. It can be seen that, in the measuring parts, the birefringence changes are growing monotonically with the deformation resulting from creep.

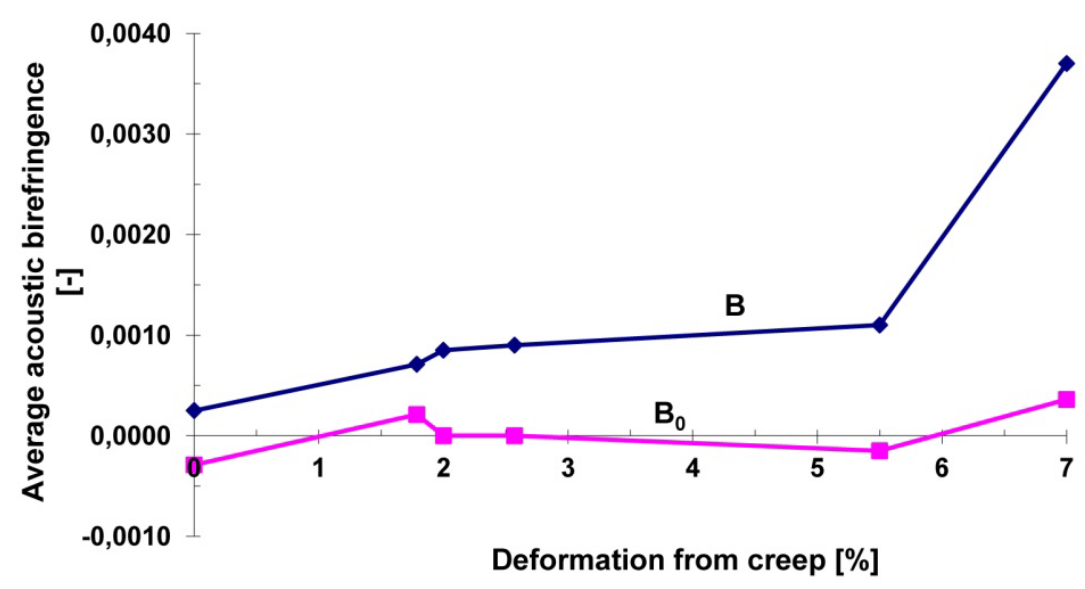

Figure 3. The average acoustic birefringence of the specimen in the measuring part $B$ and the gripping part $B_{0}$ resulting in deformation from creep of steel A336 for flat specimens [6]

\section{METHODS AND MATERIAL TESTING}

Inconel 718 was used to test and evaluate the degradation sustained. In order to obtain a certain deformation of the material samples the static tensile tests and creep tests were carried out. Specimens of varying cross-sectional area measuring part were used for the tests (Fig. 4.). Such geometry of the sample allowed researchers to obtain the area of deformation which varied along the axis of the sample. Knowledge of the permanent deformation in the given cross-section of the specimen combined with with the analysis of the structure at this point made it possible to investigate the structure of the material damage caused by permanent deformation. The proposed method enables replacing the series of specimens with one sample only. The test method and sample were patented.
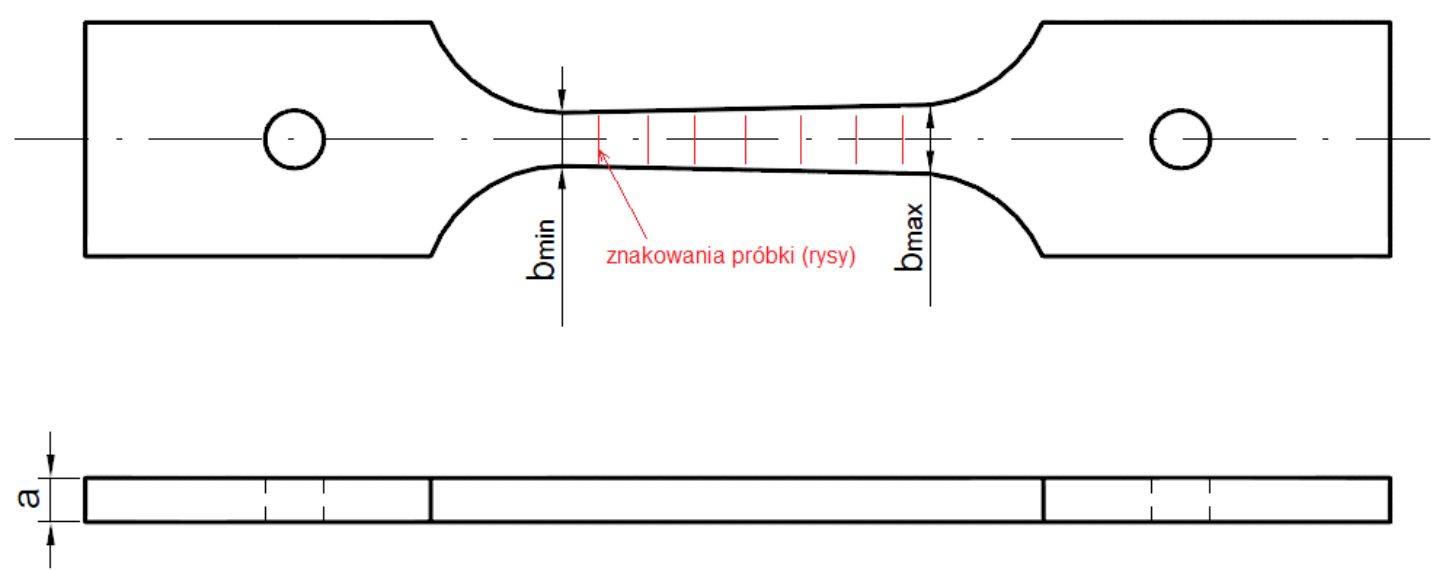

Figure 4. Specimen for tests degradation of Inconel 718 
After the creep testing and the static tensile tests, on the specimens in marked places, permanent strains in the direction of width and thickness of the sample were measured. Then, from the condition of incompressibility of the material, strain in the direction of the axis was calculated. Based on the calculated values of strain using Johnson's model [2], damage parameter $D$ is as follows:

$$
D=\sum \frac{\Delta \varepsilon}{\varepsilon^{f}}
$$

where: $\Delta \varepsilon$ is the plastic strain in the direction of the axis and $\varepsilon^{\mathrm{f}}$ is the final parameter value corresponding to the breaking of the sample.

Figure 5. shows the distribution of damage parameter calculated as a function of the distance of the fracture of the sample after the test (the distance of the smallest cross-section).

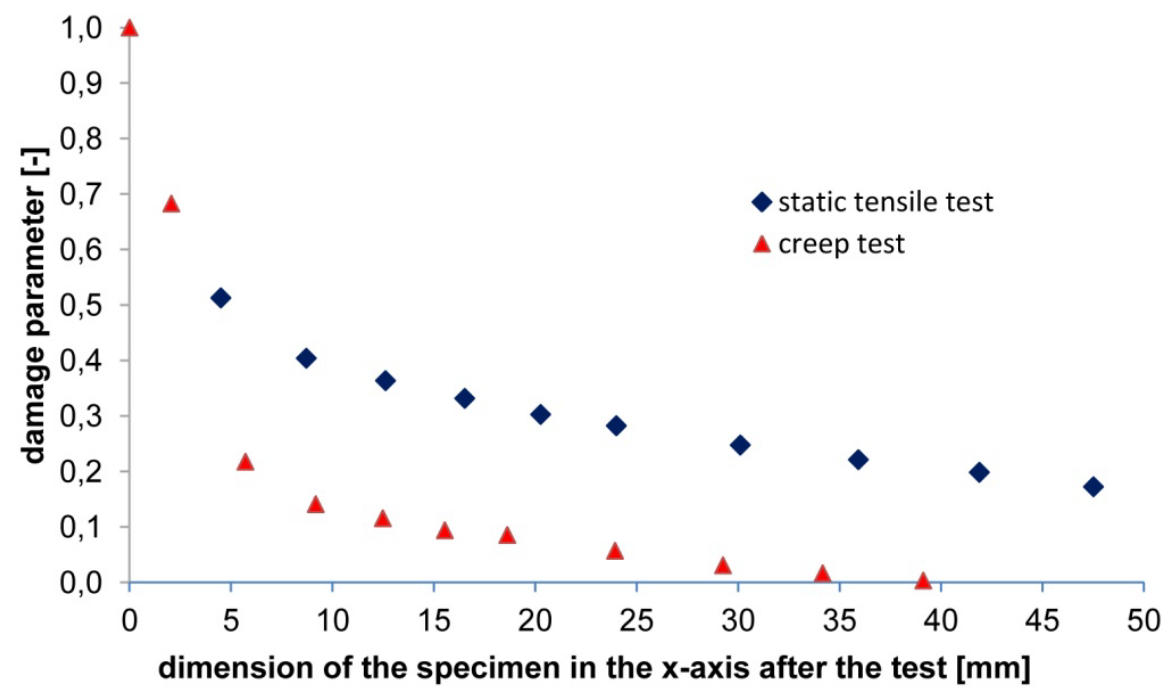

Figure 5. Damage parameter as a function of the distance from the fracture for a specimen after static tensile test and after creep test

\section{MEASUREMENTS OF ACOUSTIC BIREFRINGENCE OF INCONEL 718}

Measurements of the speed of transverse waves propagating in the thickness direction were done at two mutually perpendicular positions of the ultrasonic probe, i.e. mutually perpendicular polarization of waves. In the tests, an ultrasonic probe with a frequency of $4 \mathrm{MHz}$ was used.

The value of birefringence is defined by the following relation:

$$
B=\frac{V_{T 2}-V_{T 1}}{0,5\left(V_{T 2}+V_{T 1}\right)}
$$

where: $\mathrm{V}_{\mathrm{T} 1}, \mathrm{~V}_{\mathrm{T} 2}$ - velocity of transverse waves propagating in the direction of the sample thickness and polarized in mutually perpendicular directions.

Prior to strength tests (static tensile test and creep test), measurements of acoustic birefringence material of specimens were carried out. Measurements were made both in gripping part of the sample and in the measurement part. The average values of birefringence in the gripping part of individual specimens fell within the range between -0.0169 and -0.0151 . The average value of birefringence for all samples in this section was -0.0161 . In the case of the measuring part the average value of birefringence for all samples was -0.0151 , while the average value of the birefringence of individual samples fell in the range between -0.0149 and -0.0153 . The values of birefringence in the widest and narrowest areas of the measurement specimens were not extreme 
values and their average difference was only about 0.0002. Fig. 6. shows the values of birefringence in the measuring part of specimens before strength tests.

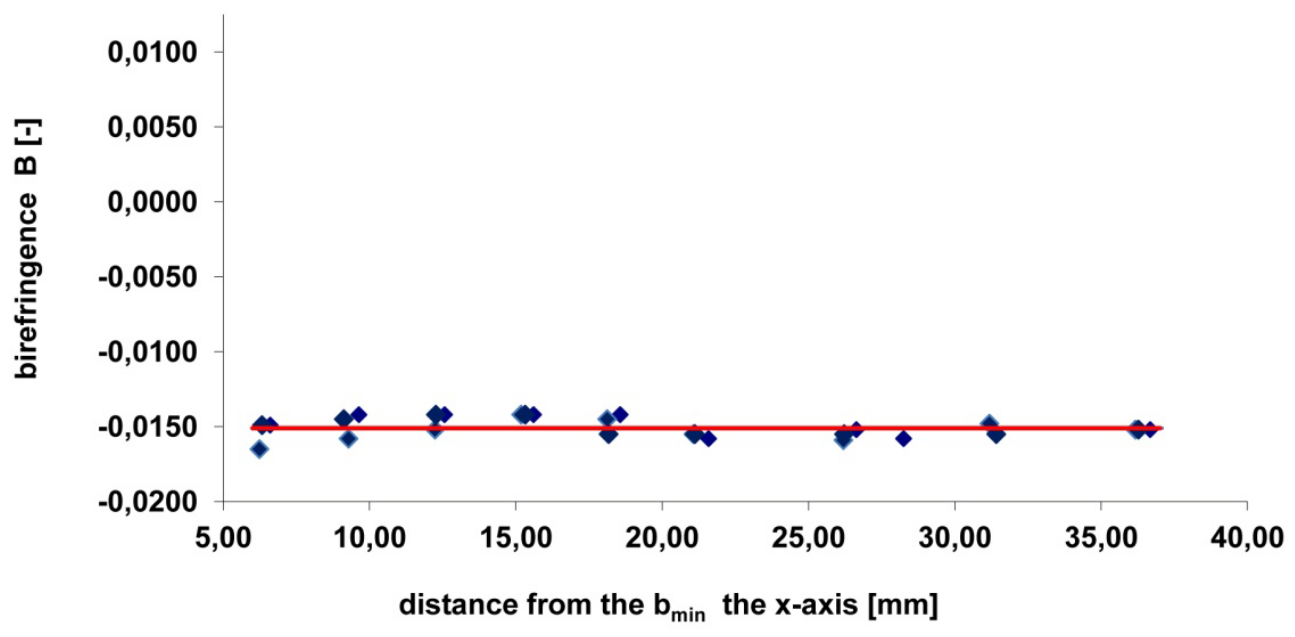

Figure 6. The values of birefringence in the measuring part of the specimens before testing

The value of acoustic birefringence after the static tensile test for the range of sample (gripping part and measurement part) was determined. The values were in the range between -0.0172 in grip section and 0.0026 for the measuring section with the greatest degree of damage. In the whole of the measuring part the range of change in birefringence was 0.0153 . In the gripping part there was a slight decrease in birefringence of approximate value of 0.0011 as compared with the results of the birefringence before the static tensile test. Change in the parameter of damage $\mathrm{D}$ was approximately 0.36 . The results of tests for the measuring part of the sample are shown in Figure 7.

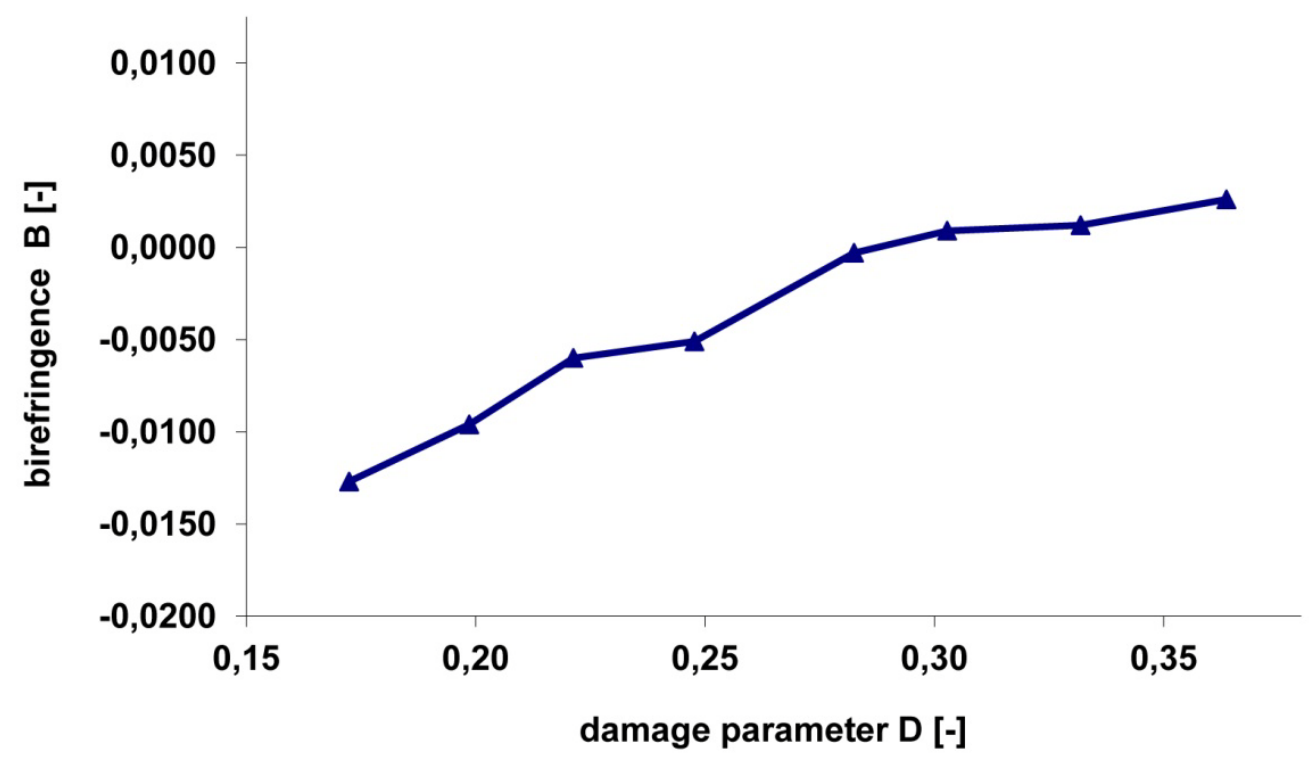

Figure 7. Changes in birefringence after a static tensile test in the measuring part of the sample depending on the parameter of damage

After a creep test, changes of acoustic birefringence were in the range between -0.0173 and -0.0122. The value of birefringence was the lowest in the gripping part. In the measuring part there was a slight increase reaching the maximum in the highest value of the parameter of damage. 
Figure 8. shows the change of birefringence $\mathrm{B}$ as a function of damage parameter $\mathrm{D}$ in the measuring part of the specimen.

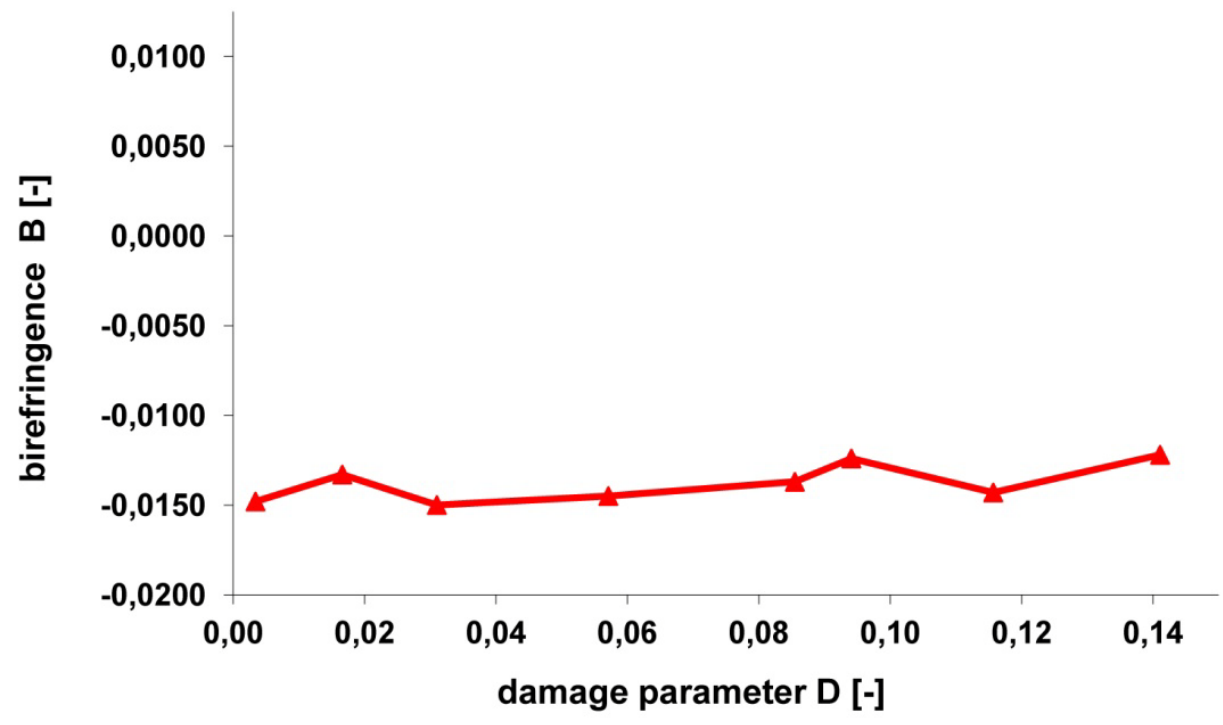

Figure 8. Changes in birefringence after a creep test in the measuring part of the sample depending on the parameter of damage.

\section{ANALYSIS OF UNCERTAINTY OF MEASUREMENTS}

Analysis was performed to investigate the influence of particular elements of the study on the results. The condition of the surface of the test specimens, the local heterogeneity of the material, the accuracy of measuring the thickness of the specimens and speed of the waves were all factors impacting the results of the tests. Taking into consideration all these elements it was estimated that the uncertainty of the measured birefringence did not exceed 0.0025 . Therefore, it was accepted that birefringence value of 0.0025 constituted a crucial factor to be taken into account when evaluating the results.

\section{SUMMARY AND CONCLUSIONS}

The specimen used in the study made it possible to obtain a continuous distribution of permanent deformations in the measuring part (from 0 to a value corresponding to rupture). To assess the degree of degradation of the material the damage parameter proposed by Johnson in 1980 was used [2]. It was noticed that there was a correlation between acoustic birefringence and damage parameter in the deformed area of the sample. No effect of the applied specimen geometry on the values of acoustic birefringence was observed. With the increased degree of material deformation, an increase in acoustic birefringence of the material was observed. This concerned both samples after creep and static tensile testing. However, the changes of acoustic birefringence after tensile tests were definitely higher than those after the creep tests. Simultaneously, the deformations of the material estimated by the damage parameter were of lower value for the specimens after creep testing than after static tensile testing. This indicates that the changes of acoustic birefringence of the material are proportional to the degree of damage. 


\section{REFERENCES}

[1] Deputat J. (1997). Nieniszczace metody badania własności materiałów, Biuro Gamma, Warszawa.

[2] Johnson G. R. (1980), Materials Characterization for computations involving severe dynamic loading, Proc. Army Symp. Of Solid Mechanics, pp. 62-67, Cape Cod, Mass.

[3] Krysztofik J., Socha G., Kukla D. (2015). Ocena stopnia uszkodzenia stopu Inconel 718 z zastosowaniem prądów wirowych, Przeglad Spawalnictwa, vol. 87, No 12 (2015)

[4] Mackiewicz S. Wykorzystanie zjawiska anizotropii akustycznej do oceny mikrouszkodzenia materiałów, www.badania-nieniszczace.info/ Badania...Nr-03.../04

[5] Socha G., Madejski B., Krysztofik J., Czarnewicz S. (2014). Sposób badania uszkodzenia struktury materiału wywołanego deformacja trwała próbki poddanej rozciaganiu i próbka do badania uszkodzenia struktury materiatu, UPRP nr P-409294

[6] Szelążek J., Kowalewski Z. L., Mackiewicz S., Deputat J. Zmiany parametrów mechanicznych i ultradźwiękowych stali w wyniku pełzania, 33 KKBN Licheń 2004 